\title{
Prevalence of Intestinal Parasites among Patients Attending a Tertiary Care Centre in Central Nepal
}

\author{
Raj Kumari Sanjana, ${ }^{1}$ Damodar Sharma, ${ }^{1}$ Brajesh Jha ${ }^{1}$ \\ ${ }^{1}$ Department of Microbiology, College of Medical Sciences, Bharatpur, Chitwan, Nepal.
}

\begin{abstract}
Background: Intestinal parasitic infections are important public health problem and are globally endemic. These parasites are responsible for the major share of morbidity and mortality in those communities where there is overcrowding, poor environmental sanitation and personal hygienic practices. Intestinal parasitic infection is highly prevalent among the general population in Nepal. This study was aimed to evaluate the burden of the intestinal parasitic infections and the pattern of distributions among patients attending in a tertiary care setting in Bharatpur, Nepal, over a period of one year (August 2017 to July 2018). Methods: Stool samples of patients received in the Microbiology laboratory, COMS that were subjected for routine stool investigations were included in this study. Naked eye physical examination, microscopic examination was carried out and parasites were identified in the received stool samples. The results were recorded, and data were entered into excel spreadsheet 2007. The percentages of the parasites present were calculated to find out the frequency and distribution. Results: A total of 1,558 fresh stool samples were screened, of which $20.60 \%(\mathrm{n}=321)$ were positive for various intestinal parasites. Overall, helminthic infections $(81.30 \%)$ were higher than protozoal infections $(18.70 \%)$. On the whole, Ascaris lumbricoides showed higher prevalence (39.56\%) followed by Ancylostoma duodenale (19.31\%) and Giardia lamblia $(9.97 \%)$. $17(1.09 \%)$ of the samples showed more than one parasite. Highest prevalence was seen in age group 15 to 25 years of age $(27.40 \%)$. Conclusions: Parasitic infection is endemic. Apart from the early diagnosis and effective treatment, health education is a requisite to control infections in this area and awareness of sanitation to reduce and control parasitic infection.
\end{abstract}

Keywords: central Nepal; helminths; infection; intestinal parasites; protozoa.

\section{INTRODUCTION}

Parasitic infections are a major health problems worldwide with one quarter of world's population suffering from it. ${ }^{1}$ The developing countries are more prone to intestinal and extra intestinal parasitic diseases. ${ }^{2}$ The frequency and incidence of intestinal parasites also varies with age, sex and geography. ${ }^{3}$ World health organization (WHO) estimated that 3.5 billion people worldwide are infected with some type of intestinal parasite, and as many as 450 million of them are sick, as a result $2,00,000$ deaths were estimated annually. ${ }^{4}$ Intra familial transmission of various pathogens can occur and can be transmitted from one family member to another, especially so if the food handler is infected. ${ }^{5}$

Like other developing countries, intestinal parasite infections are major health problem in Nepal. Epidemiologic surveys of the intestinal parasite infections are important in Nepal too because they reflect sanitary conditions of the community and produce basic data for the control of parasitosis in future. Studies conducted in rural and urban settings in various regions of Nepal showed a range from
$20.7 \%$ to $49.0 \%{ }^{6}{ }^{6}$ However, the prevalence rate for individual parasite varies from region to region. To our knowledge, no recent studies taking into account the overall prevalence of the intestinal parasites have been published previously from this part of central Nepal. Therefore, this study was conducted to determine the present distribution pattern of the intestinal parasites among patients attending a tertiary care hospital in Bharatpur, Chitwan, Central Nepal.

\section{METHODS}

A cross sectional study was carried out from period of August 2017 to July 2018 on stool samples which were received in the department of Microbiology, College of Medical Sciences, Teaching Hospital, Bharatpur, Nepal. Both outdoor as well as indoor patients were included in present study. Total 1,558 samples from the patients were included in the study. The stool samples were collected in disposable dry and clean wide mouth screw capped labeled containers without preservative. The approval from institutional Ethical Committee (COMS-IRC) was obtained. The

Correspondence: Dr. Raj Kumari Sanjana, Department of Microbiology, College of Medical Sciences, Bharatpur, Chitwan, Nepal. Email: rajkumari_sanjana@yahoo.co.in. Phone: +977-9845091643. Article Received: 2019-04-18. Article Accepted: 2019-07-06. 
sample received were subjected to complete examination both gross and microscopy within 1-2 hours of its collection. In gross examination, consistency of the stool sample, presence of mucus, blood, intestinal worm and segments of the tapeworm was noted. Microscopic examination included saline and iodine wet mount, which was observed in 10X and 40X magnifications. Negative samples were re- examined by concentration technique (Formal-ether sedimentation, Allen Ridley).

The wet mount was screened for the presence of ova and cyst of the parasite. Protozoa and helminthes were identified according to their morphological details (Garcia, 1998).

\section{RESULTS}

A total of 1,558 stool samples were examined out of which 321 were found to have intestinal parasitic infection with a prevalence rate of $20.60 \%$. Various parasites identified among the study population were helminthes and protozoans. Helminth infestations found in $265(82.55 \%)$ cases while Protozoal infestation found in $56(17.45 \%)$. Among the parasites identified Ascaris lumbricoides 127 (39.56\%), Ancylostoma duodenale 62 (19.31\%), Giardia lamblia 32(9.97\%) were the most common followed by Entamoeba histolytica 24 (7.47\%), Hymenolepsis nana 18(5.60 \%), Strongyloides stercoralis 17 (5.29\%), Taenia species $16(4.98 \%)$, Enterobius vermicularis $14(4.36 \%)$ and Trichuris trichiura $11(3.42 \%)$.

Table 1 depicts the characterization of the various parasites.

\begin{tabular}{|c|c|c|}
\hline Parasites & $\begin{array}{c}\text { Percentage } \\
\text { from total } \\
\text { cases } \\
(n=1,558)\end{array}$ & $\begin{array}{c}\text { Positive cases } \\
\text { and percent- } \\
\text { age } \\
(n=321)\end{array}$ \\
\hline Ascaris lumbricoides & $8.15 \%$ & $127(39.56 \%)$ \\
\hline $\begin{array}{l}\text { Ancylostoma duode- } \\
\text { nale }\end{array}$ & $3.98 \%$ & $62(19.31 \%)$ \\
\hline Giardia lamblia & $2.05 \%$ & $32(9.97 \%)$ \\
\hline Entamoeba histolytica & $1.54 \%$ & $24(7.47 \%)$ \\
\hline Hymenolepsis nana & $1.15 \%$ & $18(5.60 \%)$ \\
\hline $\begin{array}{l}\text { Strongyloides ster- } \\
\text { coralis }\end{array}$ & $1.09 \%$ & $17(5.29 \%)$ \\
\hline Taenia species & $1.03 \%$ & $16(4.98 \%)$ \\
\hline $\begin{array}{l}\text { Enterobius vermicu- } \\
\text { laris }\end{array}$ & $0.89 \%$ & $14(4.36 \%)$ \\
\hline Trichuris trichiura & $0.71 \%$ & $11(3.43 \%)$ \\
\hline
\end{tabular}

The overall infection rate was more in male than female with a percentage rate of $183(57.00 \%)$ and $138(42.99 \%)$ respectively (Table 2$)$. The ratio among infected male and female was 1.06:1. The highest prevalence of intestinal parasites was found in age group $15-25$ years $(27.40 \%)$ followed by age

\begin{tabular}{|lccc|}
\hline \multicolumn{4}{l}{ Table 2. Gender wise positive cases. } \\
\hline Gender & Total no. & $\begin{array}{c}\text { Positive no. } \\
\text { and \%o }\end{array}$ & P-value \\
Male & 660 & $183(57.00)$ & $<0.05$ \\
Female & 898 & $138(42.99)$ & $<0.05$ \\
Total & $\mathbf{1 , 5 5 8}$ & $\mathbf{3 2 1 ( 1 0 0 )}$ & \\
\hline
\end{tabular}

group of $6-14$ yrs $(25.36 \%)$ and in $>45$ yrs age group (22.36). It is depicted in Table 3.

\begin{tabular}{|ccc|}
\hline \multicolumn{3}{|c|}{ Table 3. Parasitic distribution in varying age group. } \\
\hline Age group & Total no. of sample & Positive sample \\
$0-5$ & 379 & $39(10.29 \%)$ \\
$6-14$ & 276 & $70(25.36 \%)$ \\
$15-25$ & 208 & $57(27.40 \%)$ \\
$26-45$ & 297 & $66(22.22 \%)$ \\
$>45$ & 398 & $89(22.36 \%)$ \\
Total & $\mathbf{1 , 5 5 8}$ & $\mathbf{3 2 1}$ \\
\hline
\end{tabular}

In this study, $19.51 \%$ of samples showed the presence of one parasite, and $1.09 \%$ of the samples showed the presence of more than one parasite, whereas; $79.40 \%$ of the samples studied showed no parasite. The parasites that were frequently observed in the co-infections were Ascaris lumbricoides, Ancylostoma duodenale and Giardia lamblia which are depicted in (Table 4).

\begin{tabular}{lcc|}
\hline $\begin{array}{l}\text { Table 4. Parasites occurring as co-infections and } \\
\text { total number identified in our study population. }\end{array}$ \\
\hline $\begin{array}{l}\text { Dual parasitic infections } \\
\text { Ascaris lumbricoides and Ancylosto- } \\
\text { ma duodenale }\end{array}$ & 4 & $(0.26 \%)$ \\
$\begin{array}{l}\text { Ascaris lumbricoides and Taenia spe- } \\
\text { cies }\end{array}$ & 3 & $(0.19 \%)$ \\
$\begin{array}{l}\text { Ancylostoma duodenale and Giardia } \\
\text { lamblia }\end{array}$ & 3 & $(0.19 \%)$ \\
$\begin{array}{l}\text { Ancylostoma duodenale and Trichu- } \\
\text { ris trichiura }\end{array}$ & 2 & $(0.12 \%)$ \\
$\begin{array}{l}\text { Taenia species and Giardia lamblia } \\
\text { Ancylostoma duodenale and Hyme- } \\
\text { nolepis nana }\end{array}$ & 2 & $(0.12 \%)$ \\
$\begin{array}{l}\text { Ancylostoma duodenale and Giardia } \\
\text { lamblia }\end{array}$ & 1 & $(0.12 \%)$ \\
\hline
\end{tabular}

\section{DISCUSSION}

Human parasitic infection is a global problem of enormous proportion with wide variation in intestinal parasite from region to region, different geographic areas, communities and ethnic groups even seasonal variation. ${ }^{7}$ Knowledge of the distribution and extent of intestinal parasitic infection in a given community is a prerequisite for planning and evaluating intervention program. It is an important public health problem worldwide predominantly in tropics, subtropics and resource poor settings. In the current study we report an overall prevalence of $20.60 \%$ with prevalence rates differing for individual parasites. It is known that the overall prevalence of these parasites in Nepal ranges from $20.7 \%$ to $49.0 \%$ as reported by Agrawal et al. ${ }^{6}$ The finding of this study was in 
agreement with previous hospital records conducted in $\mathrm{Nepa}^{8-10}$ and elsewhere in the world. ${ }^{10-11}$ However, this finding is in contrast with some previous studies conducted in Nepal. ${ }^{6,12-14}$ The wide variation in the prevalence of intestinal parasites may be due to variations in factors like quality of drinking water supply, sanitation and other environmental conditions. It might also be due to the place and time differences of the study.

In this study, in gender wise basis intestinal parasite infection rate was found higher among males $(57.00 \%)$ than females $(42.99 \%)$. The difference was found to be statistically significant $(p<0.05)$. The findings of this study was in agreement with some previous reports in Nepal. ${ }^{8,13}$ Although the finding was in contrast with some studies done elsewhere. ${ }^{15-17}$ Studies in Nepal and other countries have reported parasitic infection being gender independent. Higher prevalence among boys than girls in the study population might be due to occupation and behavioral factors. Generally increased mobility of the male or their more active and wandering nature increases the risk of infection.

Based on the age of the patients included in the study, the highest prevalence of intestinal parasitosis was found among age group of 15-25 yrs. $(27.40 \%)$, followed by $6-14$ yrs. (25.36\%) group. It was found to be lowest among age group (0-5) yrs. $(10.29 \%)$. The higher prevalence among adults and school going age group was in agreement with the previous reports. ${ }^{8-20}$ On the other hand previous studies reported higher prevalence rate among children. ${ }^{8,21,22}$ Altogether 9 species of intestinal parasites were detected, two were protozoa and the remaining seven were helminthes. In the present study Protozoan positive rate was $(17.76 \%)$, whereas Helminthis parasites were found to be $82.19 \%$ and was in higher prevalent rate. This might be due to the differences in the source of water, food habits, poor sewage system, exposure to soil etc. Our finding was in agreement with various other studies in Nepal. ${ }^{23-25}$

In the present study, among the various parasites detected the most common was Ascaris

\section{REFERENCES}

1. Kang G, Mathew MS, Rajan S. et al. Prevalence of intestinal parasites in rural India. Tropical Med and International Health. 1998; 3 (1):70-5.

2. Shaikh GS, Begum R, Hussain A et al. Prevalence of intestinal protozoan and helminth parasites in sukkur, sindh. Sindh Univ Res Journal. 2009; 4(2): 53-8

3. Ahsan-Ul-Wadood, Bari A, Rhaman A, Qasim KF. Frequency of Intestinal Parasite Infestation in Children Hospital Quetta. Pakistan J Med Res. 2005; 44(2): 87-8. lumbricoides. This finding was in agreement with previous reports. ${ }^{8,21,26}$ However it was in contrast with other similar studies in Nepal. ${ }^{8,9,13,20}$ High prevalence of Ascaris lumbricoides might be due to higher soil contamination of the organism in this area as well as higher number of population that has agricultural profession for livelihood.

Similarly among the protozoan Giardia lamblia $(10.06 \%)$ was the commonest in the study group, followed by Entamoeba histolytica (7.70\%). High prevalence of Giardia lamblia may be due to consumption of raw fecal contaminated water especially in rainy season.

The prevalence of monoparasitism was higher $(19.5 \%)$ than multiparasitism (1.09\%) in the study population. This finding was in agreement with the previous reports. ${ }^{20,27-28}$ But higher percentage of multiparasitism has also been reported. ${ }^{29}$ The higher rate of monoparasitism with Ascaris lumbricoides might be due to higher soil contamination and the major occupation of people living here being agriculture.

\section{CONCLUSIONS}

This study showed that intestinal parasitic infection is a major public health problem. It has been shown that most endemic transmission of enteric infections among communities in developing countries is not primarily via water, but instead through other routes such as contaminated food, hands and soil contacts.

The study was limited to single sample observation. Perhaps, larger sample size and longitudinal studies with more parameters must be necessary for the continuation of this surveillance study to obtain an accurate understanding and cause of parasitic burden of this area.

\section{ACKNOWLEDGEMENTS}

The author would like to thank all microbiology technical and nontechnical staffs for their kind help and support during research.

\section{Conflict of Interest: None.}

4. World Health Organization. Prevention and control of intestinal parasitin infections. WHO Technical Report Series. 1987; 749; 1-86.

5. Goodwin MH, Love GJ, Mackel DC et al. Observations of familial occurrence of diarrhea and enteric pathogens. Amer J Epidemiol. 1966; 84: 268-81.

6. Agrawal PK, Rai SK, Khanal LK et al. Intestinal parasitic infections among patients attending Nepal Medical College Teaching Hospital, Ktm, Nepal. Nepal Med Coll J. 2012; 14(2): $80-83$ 
7. Tedla S. Intestinal helminthiasis in man in Ethiopia. Helminthologia. 1986; 23: 43-8.

8. Shakya B, Bhargava D, Shreshtha S et al. Intestinal Parasitosis. J Institute of Med. 2009; 31-3.

9. Khanal LK, Rai SK, Khanal PG et al. Status of intestinal parasitosis among hospital visiting patients in Deukhury Valley, Dang, Nepal. Nepal Med Coll J. 2011; 13(2):100-2.

10. Manochitra K, Padukone S, Philips SA et al. Prevalence of intestinal parasites among Patients attending a Tertiary Care Centre in South India. Int $\mathbf{J}$ Curr Microbiol App Sci. 2016; 5(9): 190-7.

11. Kryonseppa H, Petterson T. The occurrence of human intestinal parasites in Finland. Scand J Infect Dis. 1976; 8(3): 199-202.

12. Sah RB, Bhattarai S, Yadav S et al. A study of prevalence of intestinal parasites and associated risk factors among the school children of Itahahari, Eastern Region of Nepal. J Trop Parasitol. 2013;3(2): 140-44.

13. Singh GK, Parajuli KP, Shrestha M et al. The prevalence of intestinal parasitic infestation in a tertiary care hospital- a retrospective study. Journal of Nobel med coll. 2011; 2(1): 13

14. Tiwari BR, Chaudhary R, Adhikari $\mathrm{N}$ et al. Prevalence of Intestinal Parasitic Infections among school children of Dadeldhura, Nepal. J Health Assoc Society. 2013; 3(1): 14-6.

15. Kumar P, Praveen R. Lata S. An Epidemiological profile of Human Gastrointestinal Parasites in Meerut District. Bull En Pharmacol Life Sci. 2013; 3(1):228-31.

16. Gelaw A, Anagaw B, Nigussie B et al. Prevalence of intestinal parasitic infections and risk factors among school children at the University of Gondar Community School, Northwest Ethiopia: a cross sectional study. BMC Public Health. 2013; 13: 304.

17. Patel M M, Patel P R, Gamit B et al. Prevalence of parasites infestation in Surat City of south Gujarat: a hospital based study. Nat J Comm Med. 2014; 5(3): 273-5.

18. Shakya B, Rai SK, Singh A et al. Intestinal parasitosis among the elderly people of
Kathmandu Valley, Nepal. Nepal Med Coll J. 2006; 8: 243-7.

19. Nuchpryoon S, Siriyasatien P, Kraivichiank et al. Prevalence of parasitic infection among thai patients at the King Chultalonkorn Memorial Hospital, Bangkok, Thailand. J Med Assoc Thailand. 2002; 85: 415-23.

20. Rai CK, Shreshtha A, Shah EP et al. Study of intestinal parasitosis among patients visiting Health care center in Kathmandu, Nepal. J Nepal Assoc. Med Lab Sci. 2004; 6: 48-53.

21. Rai SK, Bajracharya K, Budhathoki $\mathrm{S}$ et al. Status of intestinal parasitosis at TU Teaching Hospital. Inst Med Coll J. 2011; 13:100-2.

22. Rai SK, Sherchand JB, Bhatt DR. Study of enteropathogens and its predisposing factors in gastroenteritis suspected children attending Kanti Children Hospital, Kathmandu, Nepal. J Nepal assoc. Med Lab Sci. 2004; 6:48-53.

23. Esteevez EG, Levine JA, Warren J. Intestinal parasites in a remote village in Nepal. Clinic Microbiol J. 1983; 17: 160-1.

24. Rai SK, Gurung CK. Intestinal parasitic infection in high school children of Birgunj. Inst Med J Nepal. 1986; 8: 33-8.

25. Sharma BK, Rai SK, Rai DR et al. Prevalence of intestinal paeasitic infestation in schoo children in the northeastern part of Kath Valley, Nepal. Southeast Asian J Trop Med Public Health. 2004; 35: 501-5.

26. Shreshtha R, Maharjan M. Prevalence of intestinal helminth parasites among schoolchildren of Bhaktapur district, Nepal. Nepalese $\mathrm{J}$ of Zool. 2013; 1: 48-58.

27. Uga S, Rai SK, Kimura $\mathrm{K}$ et al. Parasites detected from diarrheal stool samples collected in Nepal. Southeast Asian Trop Med public Health. J 2004; 35: 19-23.

28. Magar DT, Rai SK, Lekhak B. study of parasitic infection among children of Sukumbasti Basti in Kathmandu valley. Nepal Med Coll J. 2011; 13: 7-10.

29. Rai SK, Matsumura T, Ono K et al. Intestinal parasitosis in an "unknown disease outbreak" in rural hilly area in Western Nepal. Nepal Med Coll J. 2001; 2: 61-4.

Citation: Sanjana RK, Sharma D, Jha B. Prevalence of Intestinal Parasites among Patients Attending a Tertiary Care Centre in Central Nepal. JCMS Nepal. 2019; 15(3):175-8. 